\title{
HEMATOLOGICAL AND IMMUNOCOMPETENCE PARAMETERS OF SUDANI, MUSCOVY DUCKS AND THEIR CROSS
}

\author{
A. Makram, A. Galal and A.H. El-Attar
}

\author{
Poultry Production Department, Faculty of Agriculture, Ain Shams University, Cairo, Egypt \\ Corresponding author: Amer Makram. E-mail: ammakram 84@yahoo.com
}

\section{SUMMARY}

The cross between Muscovy, as a commercial duck, and Sudani duck improves the carcass quality and immunity compared to commercial duck. The objective of the current study to improve the immunity of Muscovy by crossing Sudani females with Muscovy males. At 32 wks of age, the Muscovy males (M) were mated with Sudani (S) females. At 8 wk of age, 16 birds (8 males +8 females) from each strain and their cross were used to determine some blood constituents and immune response. The results revealed that $M S$ cross recorded high positive heterosis for Cell-mediated immune (CMI) response at 24, 48 and $72 \mathrm{~h}$ post PHA-P injection, and for the relative lymphoid organs weight. The MS cross recorded negative heterosis for White Blood Cells (WBCs) count, lymphocyte, monocytes and eosinophils (\%); however, there was positive hetrosis for heterophils and $H / L$ ratio. Both males and females recorded positive heterosis for CMI response at 24, 48 and $72 h$ post injection. Concerning lymphoid organs, males had positive heterosis for bursa, while the females had negative heterosis. Both males and females had positive heterosis for spleen. However, the females had higher positive heterosis compared to the males. Finally, the MS cross had higher immunological parameters and low mortality and defects rates when compared with for Muscovy duck strain. It is concluded the cross between commercial duck with Sudani ducks strains, improve the immunity in the cross compared to Muscovy as a commercial duck.

\section{Keywords: Sudani, Muscovy duck, cross, immunocompetence, hematological, heterosis}

\section{INTRODUCTION}

In the last two decades, the consumption of duck meat has rapidly increased, and it is expected that it will continue to grow in the future. Ducks are considered the second source of poultry meat in Egypt. In recent years, more attention was focused on increasing meat production through duck crossing. Sudani duck is one of the most popular birds in Egypt. It has many names in Egypt like native duck or Egyptian Muscovy. They have lower growth performance, although, Sudani ducks have higher carcass quality and immune response. Crosses between male French Muscovy and local female Muscovy ducks are popular) (El-Soukkary et al., 2005; Galal et al., 2011; Makram, 2015 and 2016; and Makram et al., 2015 and 2016). The crossbreeding of Muscovy drakes with Pekin ducks is aimed to evoking hetrosis mainly in slaughter traits. Wawro et al. (2000) observed favorable positive hetrosis in hybrids in relation to the blood content of hemoglobin and total lipids, and the activity of amino transferases in the blood. Negative hetrosis noted in relation to the cholesterol content and the activity of phosphatases in the blood serum of Mullards seems to be desirable as well. Swathi and Sudhamayee (2005) reported that hematological parameters (Hematocrit (HCT), Haemoglobuline (Hb), Red Blood Cells (RBCs)) were higher in cross breed (Khaki-Campbell x Desi) compared to Nondescript (native to Andhra Pradesh) at 18-20 wk of age. Prajapati (2009) observed that the hematological values like $\mathrm{Hb}$, Packed Cell Volume (PCV), RBCs and WBCs counts were decreased in all low pathogenic avian influenza (LPAI) affected flock as compared to normal healthy flocks. There was relative heterophilia and lymphocytopenia which indicates lymphocidal effect of virus. This experiment was designed to improve the immunity of Muscovy by crossing Sudani females with Muscovy males.

\section{MATERIALS AND METHODS}

This experiment was carried out at a private farm in Fayoum Governorate. A total number of 275 ducks (150 Sudani and 125 Muscovy) one day old un-sexed ducks were used. They were reared under similar environmental, managerial and hygienic conditions from one day old to the end of the experiment. The feed and water were offered ad libitum. They were fed a diet containing $22 \%$ crude protein (CP) and $2900 \mathrm{~K} / \mathrm{Cal}$ during the first four wks of age, $20 \% \mathrm{CP}$ and $2900 \mathrm{~K} / \mathrm{Cal}$ till marketing age. At $32 \mathrm{wk}$ of age, the seven Muscovy males (M) were allowed to natural mating with 28 Sudani (S) female (i. e. one male was mated with four females). The total number offspring produced from this mating was 115 ducklings.

\section{Measurements: \\ Blood constituents:}

At eight wk of age for parents and in the same age for the cross, 16 birds (eight males + eight females) from each strain and the cross were used. Blood samples were withdrawn from the Jugular vein during slaughtering. A portion of the blood was used for hematocrit determination using heparinzed capillary tubes and a microhematocrit centrifuge. The hematocrit figures were measured after spinning 
microhematocrit for $12 \mathrm{~min}$. The red blood cells count, haemoglobuline and thrombocytes were determined.

\section{Cell-mediated immunity assay:}

At $8 \mathrm{wk}$ of age for parents and the same age for the cross 16 birds ( 8 male +8 female) from each strain and the cross, were intradermally injected in the toe web of the left foot with $5 \mu \mathrm{g}$ phytohemagglutinin-P (PHA-P) (Sigma Chemical Co., St. Louis, MO 63178) dissolved in $0.1 \mathrm{ml}$ of sterile saline. Cell response to PHA-P was measured a constant tension caliper before injection and at 24, 48 and $72 \mathrm{hr}$ after PHA-P injection. The toe web swelling was calculated as the difference between the thickness of the toe web before and after injection.

\section{Relative lymphoid organs weight:}

After completion of PHA-P, the ducks were weighed and slaughtered. The bursa of Fabricius and spleen were removed and weighed to the nearest milligram.

\section{White blood cells count (WBCs).}

At eight wk of age, blood samples were obtained from each strain for WBCs count based on the procedures of Gross and Siegel (1983). Briefly, one drop of blood being smeared on each of glass slides. The smears were stained using Wrights stain. Leukocytes in birds blood include lymphocytes, Monocytes and granulocytes. The granulocytes are further classified as heterophils, eosinophils, and basophiles (Terry and Ellis, 2007).

\section{Mortality and Defects:}

The mortality and defects (short beak- neck defect- legs defect- dwarfism) were recorded after first week of age to the marketing age in birds during the experimental period for each strain and the cross.

\section{Heterosis:}

The crossbreed effect (Hybrid vigor) or hetrosis expressed as a percent was calculated as the superiority of the cross breed ducks over that of the pure bred ones. The heterosis was calculated as follows (Wawro et al., 2000):

Mean cross breed (XC) - Mean pure breed (XP)

Heterosis $\%=\frac{\text { Mean pure breed (XP) }}{\mathrm{X}} 100$

\section{Statistical analysis:}

Data were subjected to a two-way analysis of variance with strain and sex with interaction using General Linear Model (GLM) procedure of SAS (2001) using the following model

$\mathbf{Y}_{\mathrm{ij}}=\boldsymbol{\mu}+\mathbf{S}_{\mathrm{i}}+\mathbf{T}_{\mathbf{j}}+[\mathbf{S x T}]_{\mathrm{ij}}+\mathbf{e}_{\mathrm{ijk}}$

Where; $\mathrm{Y}_{\mathrm{ij}}=$ Trait measured, $\mu=$ Overall mean, $\mathrm{S}_{\mathrm{i}}=$ Strain effect $(i=1,2,3,4$ and $5 \cdot(\mathrm{T} j=\operatorname{sex}$ effect $(j=1$ and 2) $[\mathrm{SxT}] \mathrm{ij}=$ Interaction between strain and sex, eijk $=$ Experimental error.

When significant differences among means were found, means were separated using Duncan's multiple range tests (Duncan, 1955).

\section{RESULTS AND DISCUSSION}

\section{Blood Parameters:}

The effect of strain, sex and their interaction on some blood constituents of MS cross and their parent are summarized in Table (1). Significant difference among duck strains for hematocrit level, where MS cross ducklings had the significantly lowest hematocrit level compared to their parents. With respect to sex effect, the males had significantly higher hematocrit value compared to females. The higher hematocrit level may enhance oxygen delivery to the tissue. Also, this increment is supposed to be a factor for increased blood volume as a reaction to increased body oxygen requirement. (Manning et al., 1990). With respect to (RBCs and thrombocytes, the MS cross had significantly lowest RBCs and thrombocytes compared to their parents, no significant difference between males and females for RBCs and plate cells, RBCs significantly affected by interaction between sex and strain.

Table 1. Effect of sex and strain on blood constituent (Means \pm SE) of Sudani, Muscovy, and their cross

\begin{tabular}{|c|c|c|c|c|c|c|c|c|}
\hline \multirow[b]{2}{*}{ Traits } & \multirow[b]{2}{*}{ Sex (Sx) } & \multicolumn{2}{|c|}{ Strains (St) } & \multirow[b]{2}{*}{ MS } & \multirow[b]{2}{*}{ Overall } & \multicolumn{3}{|c|}{ Level of significant } \\
\hline & & $\begin{array}{c}\text { Muscovy } \\
\text { (M) }\end{array}$ & $\begin{array}{l}\text { Sudani } \\
\text { (S) }\end{array}$ & & & $\mathbf{S t}$ & Sx & $\mathbf{S t} * \mathbf{S x}$ \\
\hline \multirow[t]{5}{*}{ HCT } & Male & 55.00 & 51.75 & 41.40 & & & & \\
\hline & & \pm 2.53 & \pm 2.00 & \pm 0.40 & $50.05^{a}$ & & & \\
\hline & Female & 52.67 & 47.20 & 37.63 & $4 a^{\mathrm{b}}$ & & & \\
\hline & & \pm 1.98 & \pm 2.94 & \pm 0.26 & $44.90^{\circ}$ & & & \\
\hline & Overall & $53.83^{\mathrm{a}}$ & $50.00^{\mathrm{a}}$ & $39.08^{\mathrm{b}}$ & & 0.0001 & 0.02 & 0.05 \\
\hline \multirow[t]{5}{*}{ RBCs } & Male & 4.68 & 4.54 & 3.19 & & & & \\
\hline & & \pm 0.13 & \pm 0.19 & \pm 0.09 & 4.23 & & & \\
\hline & Female & 4.58 & 4.17 & 3.52 & 4.03 & & & \\
\hline & & \pm 0.11 & \pm 0.16 & \pm 0.07 & & & & \\
\hline & Overall & $4.63^{\mathrm{a}}$ & $4.40^{\mathrm{a}}$ & $3.39^{\mathrm{b}}$ & & 0.0001 & NS & 0.05 \\
\hline \multirow[t]{5}{*}{ Thrombocytes } & Male & 54.00 & 50.00 & 42.80 & 1927 & & & \\
\hline & & \pm 2.22 & \pm 2.83 & \pm 1.77 & 49.37 & & & \\
\hline & Female & 53.500 & 52.80 & 48.13 & & & & \\
\hline & & \pm 1.76 & \pm 2.63 & \pm 2.96 & 51.05 & 0.02 & NS & NS \\
\hline & Overall & $53.75^{\mathrm{a}}$ & $51.08^{\mathrm{ab}}$ & $46.08^{\mathrm{b}}$ & & & & \\
\hline
\end{tabular}


Immunocompetence parameters:

\section{Cell-mediated immunity (CMI):}

The effect of strain, sex and their interaction on cell-mediated immunity is presented in Table (2) and Figures (1 and 2). The results revealed that PHA-P injection at 24 and $48 \mathrm{~h}$ post injection showed marked differences between strains. The Sudani and MS cross had significantly higher response to PHA-P injection compared to Muscovy ones at all measured times. With respect to sex effect, it could be noticed that the males had significantly higher response to PHA-P injection at $48 \mathrm{~h}$ and $72 \mathrm{~h}$ post injection, however no significant differences were observed at $24 \mathrm{~h}$ between male sand females. The PHA-P intradermally reaction, a T-lymphocyte-dependent response, has been well researched and has been shown to be a reliable indicator of in vivo cellular immunity in poultry (Goto et al., 1978). The skin response reflects a complex series of physiological events such as mitogen-receptor and lymphocytemacrophage interactions, release of chemical mediators, cellular proliferation, and changes in vascularity (Chandra and Newberne (1977).

Table 2. Effect of sex and strains on Toe-web swelling (difference) of Sudani, Muscovy, and their cross

\begin{tabular}{|c|c|c|c|c|c|c|c|c|}
\hline \multirow[b]{2}{*}{ Traits } & \multirow[b]{2}{*}{ Sex (Sx) } & \multicolumn{3}{|c|}{ Strains (St) } & \multirow[b]{2}{*}{ Overall } & \multicolumn{3}{|c|}{ Level of significant } \\
\hline & & $\begin{array}{c}\text { Muscovy } \\
\text { (M) }\end{array}$ & $\begin{array}{c}\text { Sudani } \\
\text { (S) }\end{array}$ & MS & & St & $\mathbf{S x}$ & $\mathbf{S t} * \mathbf{S x}$ \\
\hline \multirow[t]{5}{*}{ D1 } & Male & 0.406 & 0.590 & 0.776 & & & & \\
\hline & & \pm 0.111 & \pm 0.125 & \pm 0.155 & 0.498 & & & \\
\hline & Female & 0.356 & 0.585 & 0.711 & & & & \\
\hline & & \pm 0.165 & \pm 0.128 & \pm 0.144 & 0.432 & & & \\
\hline & Overall & $0.381^{\mathrm{b}}$ & $0.587^{\mathrm{ab}}$ & $0.743^{\mathrm{a}}$ & & 0.05 & NS & NS \\
\hline \multirow[t]{5}{*}{ D2 } & Male & 0.135 & 0.491 & 0.665 & $0473^{\mathrm{a}}$ & & & \\
\hline & & \pm 0.055 & \pm 0.129 & \pm 0.124 & 0.473 & & & \\
\hline & Female & 0.092 & 0.312 & 0.286 & $0249^{b}$ & & & \\
\hline & & \pm 0.033 & \pm 0.092 & \pm 0.065 & $0.249^{\circ}$ & & & \\
\hline & Overall & $0.114^{\mathrm{b}}$ & $0.402^{\mathrm{a}}$ & $0.475^{\mathrm{a}}$ & & 0.006 & 0.01 & NS \\
\hline \multirow[t]{5}{*}{ D3 } & Male & 0.098 & 0.273 & 0.327 & $252^{\mathrm{a}}$ & & & \\
\hline & & \pm 0.052 & \pm 0.101 & \pm 0.116 & $0.252^{a}$ & & & \\
\hline & Female & 0.048 & 0.120 & 0.134 & $0108^{b}$ & & & \\
\hline & & \pm 0.025 & \pm 0.046 & \pm 0.047 & 0.108 & & & \\
\hline & Overall & 0.073 & 0.196 & 0.230 & & NS & 0.04 & NS \\
\hline
\end{tabular}

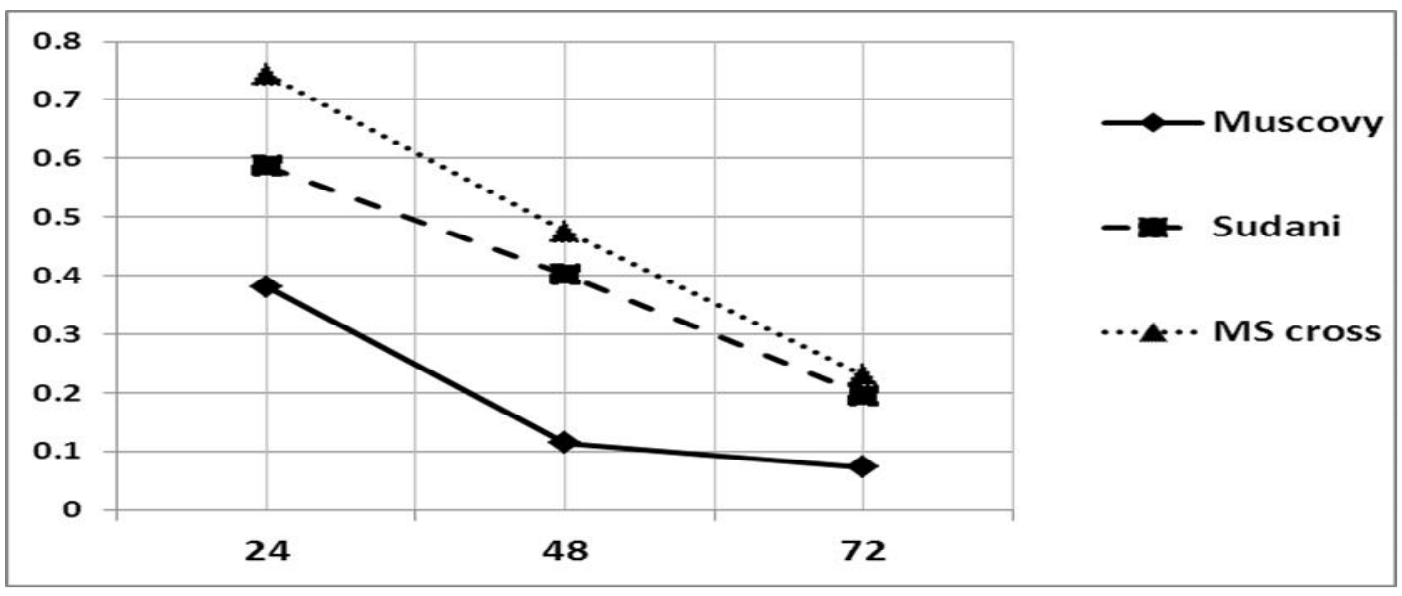

Fig. 1. Toe-web swelling (difference) (mm) Muscovy, Sudani duck strains and their cross. 


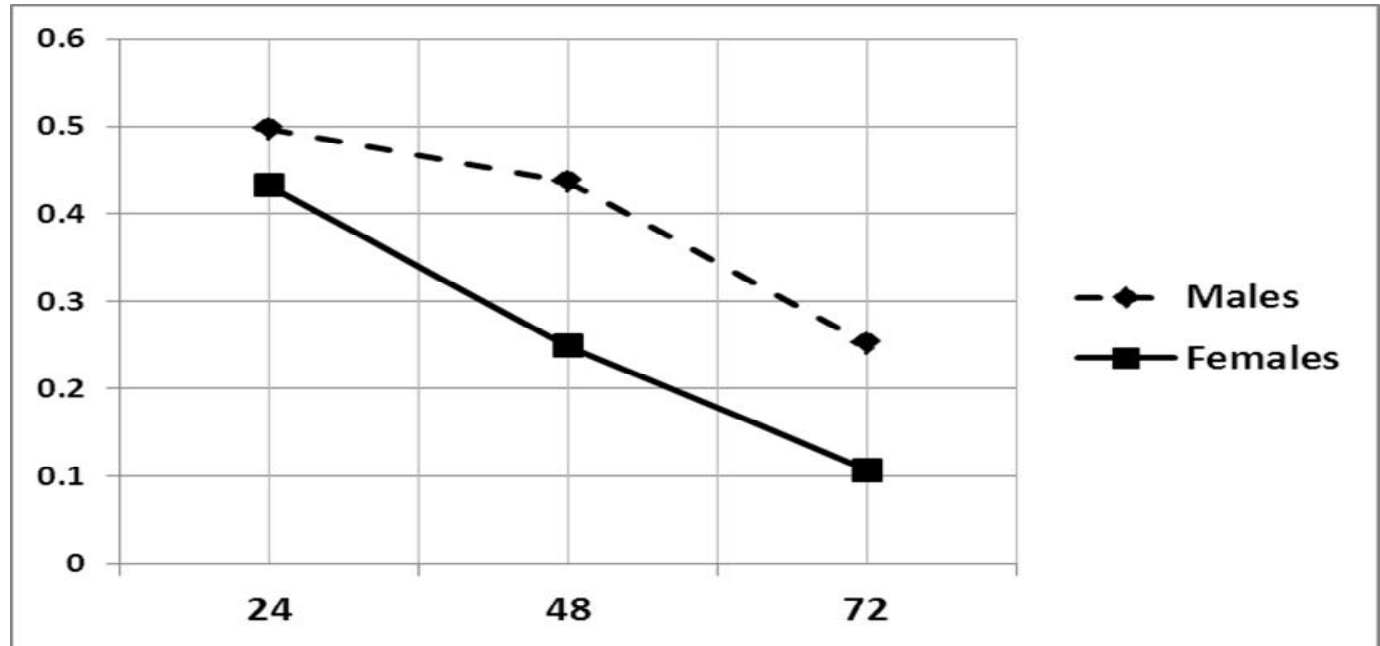

Fig. 2. Effect of Sex on Toe-web swelling thickness (mm) of Sudani, Muscovy, and MS

Relative lymphoid organs weight :

Effect of strain, sex and their interaction on relative lymphoid organs is summarized in Figure (3, 4 and 5). It could be notice that the Muscovy duck strain had significantly lowest spleen and bursa percentages compared to Sudani and MS cross. Also, there was significant difference between sexes. The relative bursa weight of males duck had significantly higher than females one. Opposite trend was noticed for spleen, the female had significantly higher spleen percentage compared to males. With respect to interaction between strain and sex, it could be noticed that the relative weight of bursa and spleen had significantly affected by interaction between strain and sex Bursa of Fabricius size may not necessarily be associated with antibody titers. Yamamoto and Glick (1982) observed in a chicken line selected for small bursa size that it had a higher total and 2mercaptoethanol-resistant antibody titers in the secondary response compared to their counterparts in the line selected for large bursa size. The spleen performs a number of non-immunological functions including filtration of the blood stream (Miller and Qureshi, 1991)..

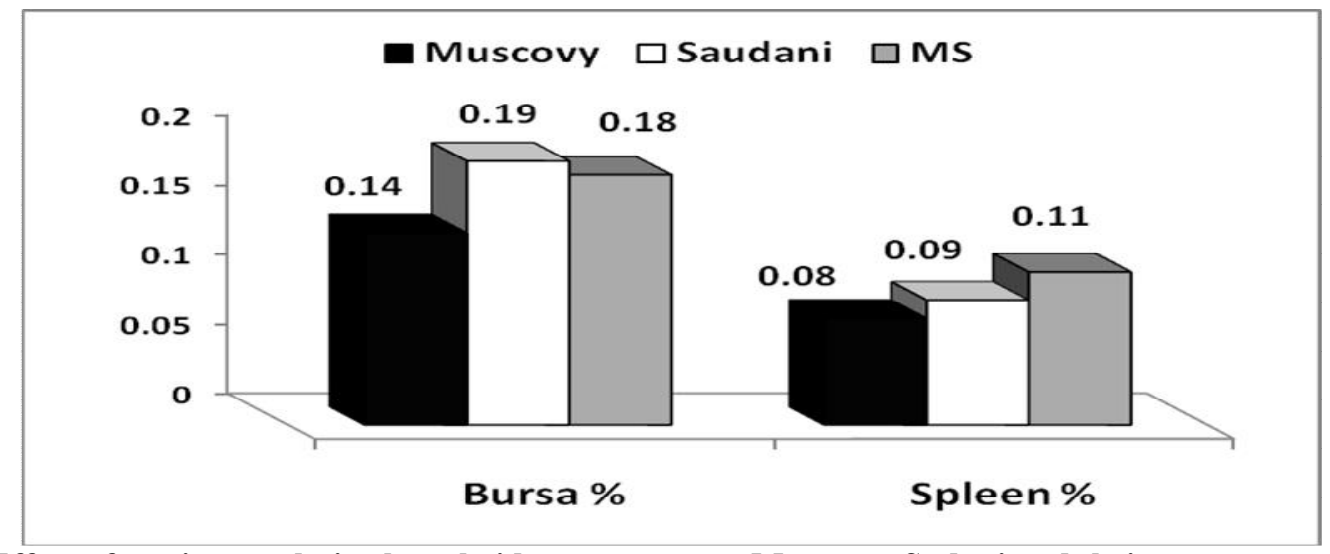

Fig. 3. Effect of strain on relative lymphoid organs among Muscovy, Sudani and their cross

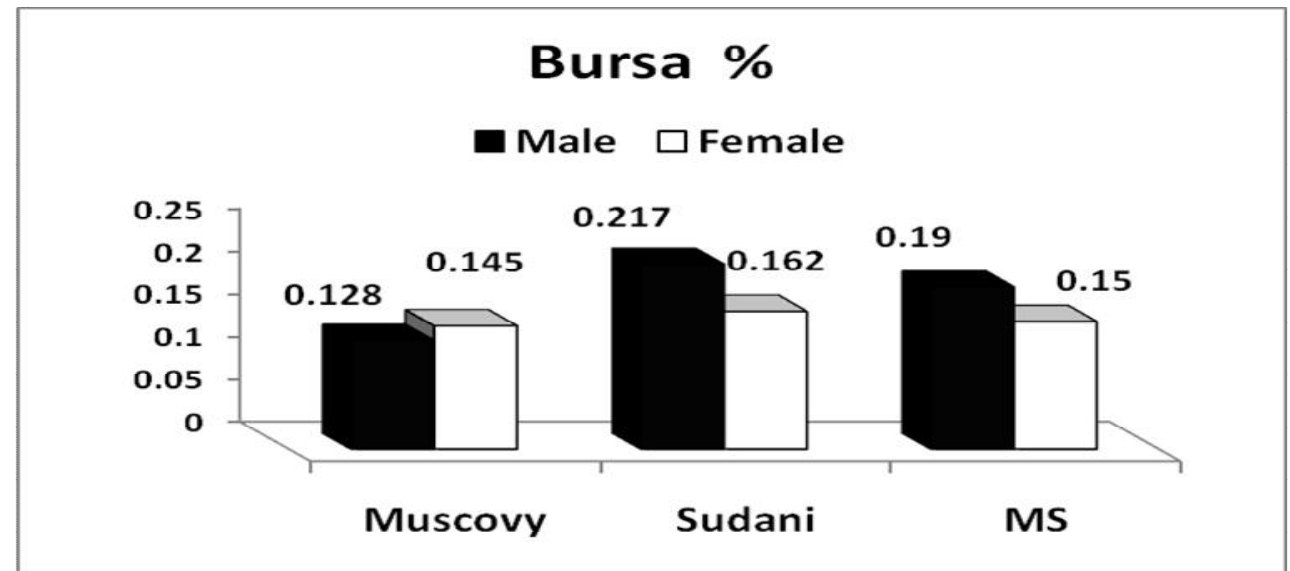

Fig. 4. Effect of sex on relative bursa weight of Muscovy, Sudani and their cross 


\section{Spleen \%}
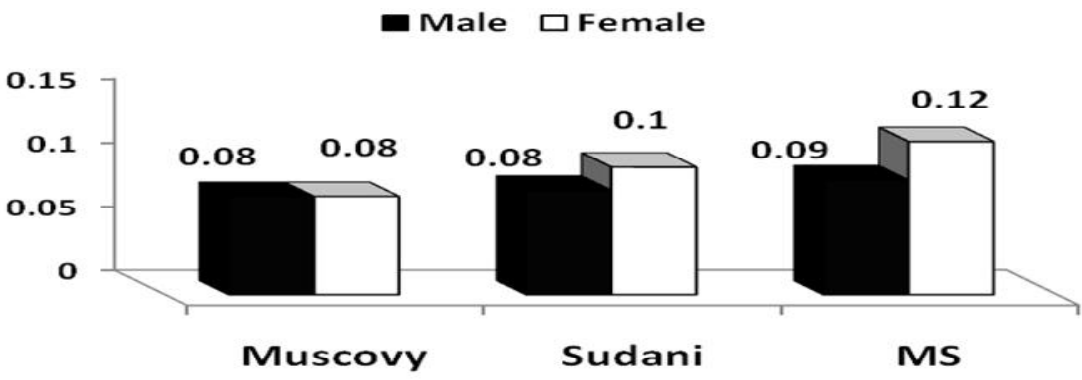

Fig. 5. Effect of sex on relative spleen weight of Muscovy, Sudani and their cross.

\section{White blood cells count:}

Effect of strain, sex and their interaction on white blood cells counted differential is presented in Table (3). It could be noticed that the MS cross had lowest WBCs count compared to Muscovy and Sudani duck strains. With respect to sex effect, the results showed that the WBCs were not significantly affected by sex. Similar trend was observed for the interaction between sex and strain. With regard to Monocytes and Eosinophils (\%), similar trend was noticed for strain effect. The eosinophils (\%) were significantly affected by sex, where males had significantly higher eosinophils (\%) compared to females ones. The corresponding figures were 3.32 and 2.07 for male and female, respectively. The present results showed that heterophils and lymphocytes (\%) were significantly affected by strain. The MS cross was significantly higher for heterophils (\%) compared to their parent. Concerning lymphocytes $(\%)$, it could be speculated that the Sudani and Muscovy duck strains were significantly higher lymphocytes (\%) compared to MS cross. $\mathrm{H} / \mathrm{L}$ ratio was significantly affected by strain, the MS cross had significantly higher $\mathrm{H} / \mathrm{L}$ ratio compared to Sudani and Muscovy duck strains, with respect the sex effect, males had significantly higher $\mathrm{H} / \mathrm{L}$ ratio compared to females ones, however the interaction was significant. Makram et al. (2014) found that the cross between Pekin with Sudani females was significantly lower for $\mathrm{H} / \mathrm{L}$ ratio

Table 3. White blood cells count (Means \pm SE) of Sudani, Peking and MS cross

\begin{tabular}{|c|c|c|c|c|c|c|c|c|}
\hline \multirow[b]{2}{*}{ Traits } & \multirow[b]{2}{*}{$\begin{array}{l}\text { Sex } \\
(\mathbf{S x})\end{array}$} & \multicolumn{3}{|c|}{ Strains (St) } & \multirow[b]{2}{*}{ Overall } & \multicolumn{3}{|c|}{ Level of significant } \\
\hline & & $\begin{array}{l}\text { Sudani } \\
\text { (S) }\end{array}$ & $\begin{array}{c}\text { Muscovy } \\
\text { (M) }\end{array}$ & MS & & St & Sx & $\mathbf{S t} * \mathbf{S x}$ \\
\hline \multirow[t]{6}{*}{ WBCs } & Male & 15.31 & 15.933 & 13.16 & 15.28 & & & \\
\hline & & \pm 0.47 & \pm 0.39 & \pm 0.66 & & & & \\
\hline & Female & 16.34 & 16.92 & 13.38 & 14.92 & & & \\
\hline & & \pm 0.37 & \pm 0.40 & \pm 0.72 & & & & \\
\hline & Overall & $15.708^{\mathrm{ab}}$ & $16.425^{\mathrm{a}}$ & $13.294^{\mathrm{b}}$ & & 0.0001 & NS & NS \\
\hline & Male & 4.38 & 4.50 & 4.00 & 4.116 & & & \\
\hline \multirow[t]{5}{*}{ Monocytes } & & \pm 0.32 & \pm 0.34 & \pm 0.32 & & & & \\
\hline & Female & 4.20 & 5.167 & 3.88 & 4.368 & & & \\
\hline & & \pm 0.37 & \pm 0.31 & \pm 0.23 & & & & \\
\hline & Overall & $4.308^{\mathrm{ab}}$ & $4.833^{\mathrm{a}}$ & $3.923^{\mathrm{b}}$ & & 0.02 & NS & NS \\
\hline & Male & 3.25 & 3.83 & 2.80 & $3.32^{\mathrm{a}}$ & & & \\
\hline \multirow[t]{4}{*}{ Eosinophils } & & \pm 0.16 & \pm 0.17 & \pm 0.20 & & & & \\
\hline & Female & 3.25 & 3.33 & 2.00 & $2.07^{\mathrm{b}}$ & & & \\
\hline & & \pm 0.16 & \pm 0.21 & \pm 0.22 & & & & \\
\hline & Overall & $3.15^{\mathrm{a}}$ & $3.58^{\mathrm{a}}$ & $2.31^{\mathrm{b}}$ & & 0.0001 & 0.0002 & NS \\
\hline \multirow[t]{5}{*}{ Heterophils } & Male & 26.00 & 28.67 & 37.60 & 29.90 & & & \\
\hline & & \pm 1.253 & \pm 0.882 & \pm 0.510 & & & & \\
\hline & Female & 26.80 & 24.67 & 31.13 & 27.95 & & & \\
\hline & & \pm 0.49 & \pm 1.45 & \pm 2.326 & & & & \\
\hline & Overall & $26.31^{\mathrm{b}}$ & $26.67^{b}$ & $33.62^{\mathrm{a}}$ & & 0.001 & NS & NS \\
\hline \multirow[t]{5}{*}{ Lymphocyte } & Male & 66.38 & 63.00 & 55.60 & 62.474 & & & \\
\hline & & \pm 1.30 & \pm 0.97 & \pm 0.510 & & & & \\
\hline & Female & 66.00 & 66.83 & 63.00 & 65.00 & & & \\
\hline & & \pm 0.847 & \pm 1.45 & \pm 2.33 & & & & \\
\hline & Overall & $66.23^{\mathrm{a}}$ & $64.92^{\mathrm{a}}$ & $60.15^{\mathrm{b}}$ & & 0.0002 & NS & NS \\
\hline \multirow[t]{5}{*}{ H/L Ratio } & Male & 39.54 & 45.66 & 67.68 & $47.877^{\mathrm{a}}$ & & & \\
\hline & & \pm 2.72 & \pm 2.11 & \pm 1.51 & & & & \\
\hline & Female & 40.67 & 37.24 & 50.67 & $43.796^{\mathrm{b}}$ & & & \\
\hline & & \pm 1.23 & \pm 3.15 & \pm 5.09 & & & & \\
\hline & Overall & $39.97^{\mathrm{b}}$ & $41.45^{b}$ & $55.21^{\mathrm{a}}$ & & 0.001 & 0.008 & 0.05 \\
\hline
\end{tabular}




\section{Mortality and Defects:}

Date presented in Figures (6 and 7) showed that the mortality rate and defects of Muscovy strain were higher than those belonging either for Sudani or MS cross. Baruah et al. (1993), Rashid et al. (2002) confirmed that the cross breeding with local CharaChembelli had (when cross with Peking and KhakiCampbell) a distinct beneficial effect on survivability, which agreed well with the findings of the above statement They indicated that ducklings produced from the crosses of local Chara-Chembelli were more adaptable to the adverse condition than pure Pekin or Khaki Campbell. Performance index was highest in pure breed (PXP) followed by its cross with Chara-Chembelli and other crossbred as well as purebreds. This result also corresponds to the findings of Rashid et al. (2002).

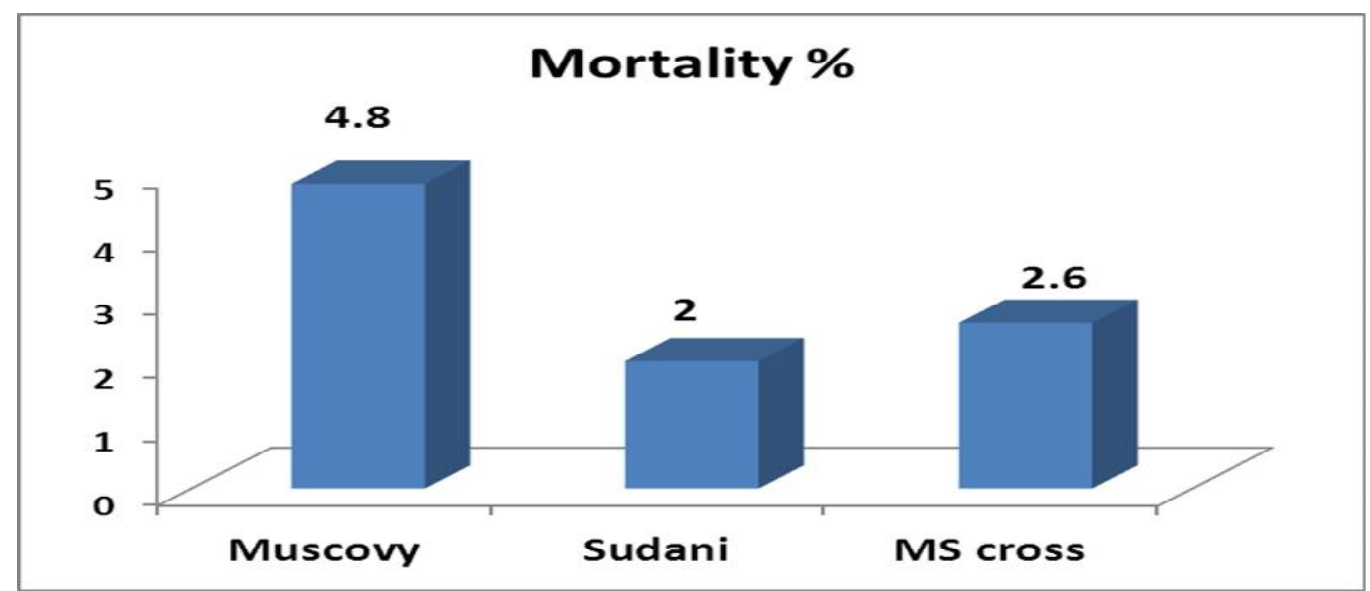

Fig. 6. Mortality percentage of Sudani, Muscovy and their cross (Offspring flock).

Birds number: Muscovy $=125$, Sudani $=150$ and $M S=115$, Mortality number: Muscovy $=6, \quad$ Sudani $=3$ and $\mathrm{MS}=\mathbf{3}$

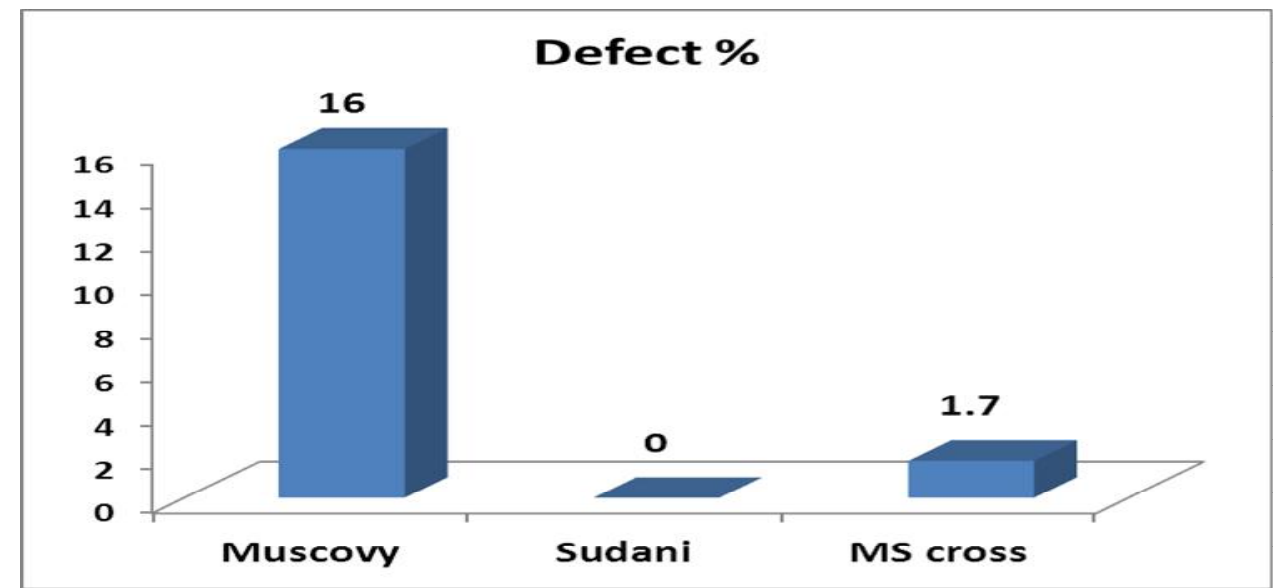

Fig. 7. Defects percentage of Sudani, Muscovy and their cross (Offspring flock).

Birds number: Muscovy $=125$, Sudani $=150$ and $M S=125$. Defect number: Muscovy $=20$, Sudani $=0$ and MS $=2$

\section{Hetrosis:}

\section{Cross effect:}

Effect of heterosis on hematological and immunocompetence is presented in Table (4). The present results showed that negative heterosis for HCT, RBCs and thrombocytes. With respect to immunocompetence, the MS cross recorded high positive heterosis for cell mediated immunity (CMI) response $(53.25,43.30$ and $93.7 \%$ at 24,48 and $72 \mathrm{~h}$ post injection, respectively) and relative lymphoid organs (9.67 and $30.95 \%$ for bursa and spleen respectively). Concerning WBCs count, MS cross recorded negative heterosis for WBCs count, lymphocyte, monocytes and eosinophils (\%); however, there was positive hetrosis for heterophils and $\mathrm{H} / \mathrm{L}$ ratio.

Wawro et al. (2000) observed favorable positive heterosis in hybrids in relation to the blood content of hemoglobin and total lipids, and the activity of amino transferases in the blood. Negative heterosis noted in relation to the cholesterol content and the activity of phosphates in the blood serum of Mullards seems to be desirable as well.

\section{Sex effect:}

Effect of sex on heterosis of hematological and immunocompetence of MS cross are summarized in Table (4). Negative heterosis for HCT, RBCs and 
thrombocytes for males and females was recorded. With respect to immunocompetence, both male and female recorded positive heterosis for CMI response, $29.9,56.26$ and $24.04 \%$ for males and $(55.64,8.86$ and $36.78 \%$ ) of females at 24, 48 and $72 \mathrm{~h}$ post injection, respectively. Concerning lymphoid organs, males had positive heterosis for bursa $(10.14 \%)$, while the females had negative heterosis $(-2.22 \%)$. Both males and females had positive heterosis for spleen, however the females had higher positive heterosis $(33.30 \%)$ compared to males $(12.54 \%)$. With respect to WBCs count, both male and females recorded negative heterosis for total WBCs, lymphocytes monocytes and eosinophils, however, males and females were positive heterosis for heterophils and $\mathrm{H} / \mathrm{L}$ ratio, males had high positive heterosis for $\mathrm{H} / \mathrm{L}$ ratio $(70.49 \%)$ compared to female $(21.79 \%)$.

Table 4. Effect of sex on heterosis (\%) of hematological and immuno competence of MS cross

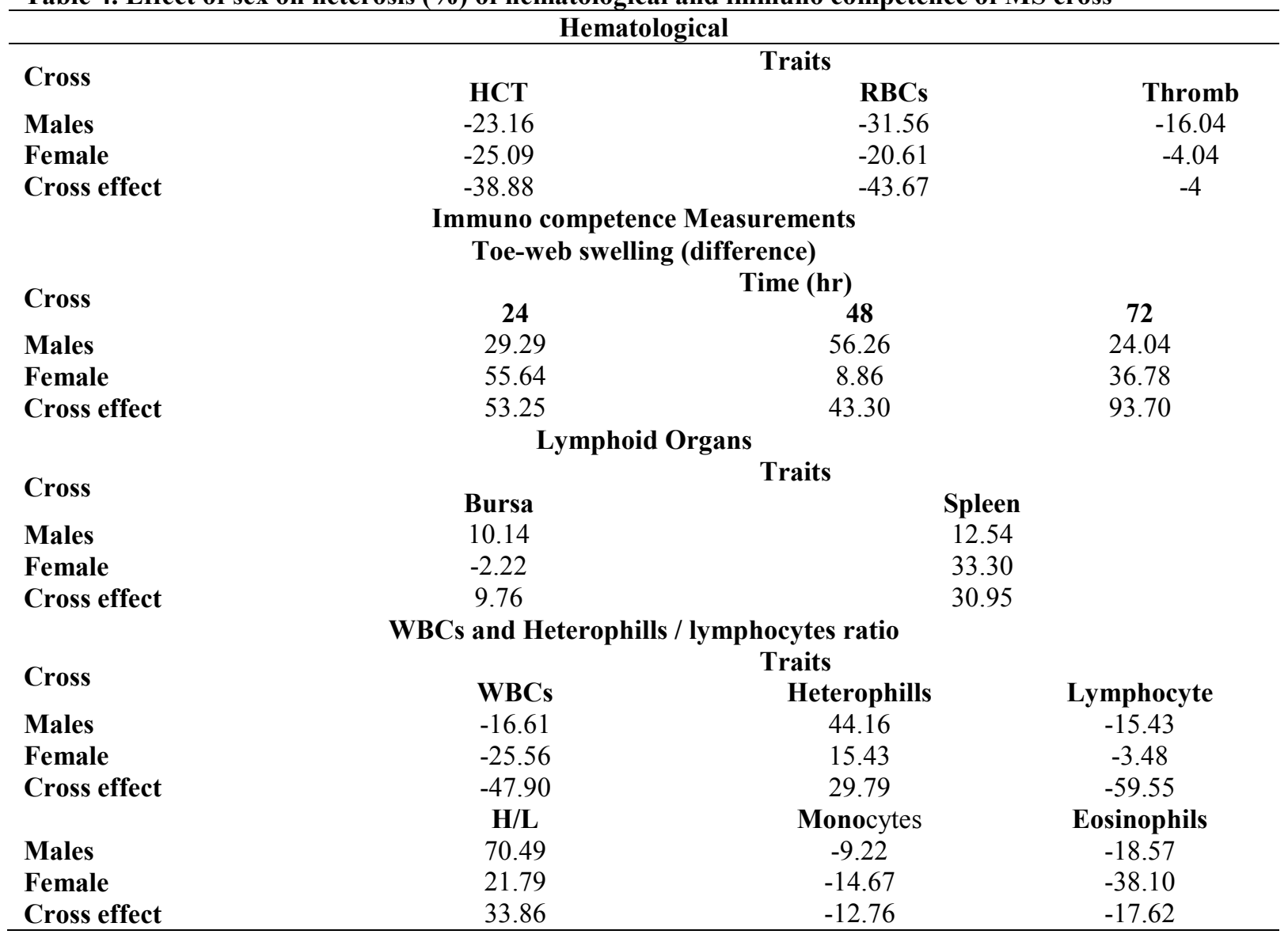

\section{CONCLUSION}

The MS cross had higher immunity and low mortality and defects rates when compared to Muscovy duck strain. The MS cross unsterile birds can be improved for several generations through crossing with their parents.

\section{REFERENCES}

Baruah, K.K., P.K. Sharma, and N. N. Bora, 1993. Mortality patterns of indigenous and Khaki Campbell ducks and their cross. Indian J. Poult. Sci. 28(11):74-76.

Chandra, R. K. and P. M. Newberne, 1977, Nutrition, immunity, and infections. Plenum Press, New York.

Duncan, D. B, 1955. Multiple Range and Multiple F Tests. Biometrics 11:1.
El-Soukkary, F. A., H. M. Mohamed, A. A. Dawood and S. Y. Abd-El Sayed, 2005. Physico-chemical, microbiological and lipid characteristics of duck meat. Minufiya J. Agric. Res., 30: 527-548.

Galal, A., W.A.H. Ali, A.M.H. Ahmed and Kh. A.A. Ali, 2011. Performance and carcass characteristics of Domyati, Muscovy, Peking and Sudani duck breed. Egypt. J. Anim. 48(2):191-202.

Goto, N., H. Kodama, K. Okada and Y. Fujimoto, 1978. Suppression of phytohemagglutinin skin response in thymoectomized chicken. Poult. Sci., 57: 246-250.

Gross, W.B. and P.B Siegel, 1983. Evaluation of the heterophil/lymphocyte ratio as a measure of stress in chickens. Avian Dis. 27: 972-979.

Makram, A, A. Galal and A. H. EL-Attar, 2014. Hematological and Immunocompetence in Peking, Sudani Duck Strains and Their Cross .The 7th International Poultry Conference (Oral 
Presentation) 3- 6 November, Ain Sukhna, Red Sea - Egypt.192-207

Makram, A., 2015. Improving the productive performance of native duck breed by crossing with standard commercial duck breed. PhD, thesis. Faculty of Agriculture, Ain Shams Univ, Egypt.

Makram, A., A. H. EL-Attar and A. Galal, 2015. The developed hybrids from the Egyptian Muscovy duck (Sudani duck). Book, lambert. ISBN, 978-3659-78415-6.

Makram. A., 2016. Ducks world (Review Article). The 9th International Poultry Conference from 710 November.463-486.

Makram. A., A. Galal and A. H. EL-Attar, 2016. Hematological and Immunocompetence Parameters Comparison between Two Crosses from Sudani Duck (Egyptian Muscovy) .The 9th International Poultry Conference from 7-10 November.219-232.

Manning, R. O., H. L. Marks and O. J. Fletcher, 1990. Effects of diettray aflatoxin in aflatixinresistance and control lines of chickens. Poultry .Sci .69:922-928.
Miller, L. and M. A. Qureshi, 1991. Comparisons of macrophage function in several commercial broiler genetic lines. Poultry Sci., 70: 1094-1101.

Rashid Abdur, M. D., M. D. Abu Jafar, M. D. Ferdaus, A. Islam, and B. M. Hassin, 2002. Evaluation of the growth performance of different duck reared under identical feeding and management. Indian J. Anim. Nutr. 19 (1) 63-68.

SAS Institute, 2001. SAS/STAT User's Guide Version 8.2 ed: Statistics. SAS Institute Inc., Cary, NC.

Terry W. C., and C. K, Ellis, 2007. Avian and exotic animal hematology and cytology .Book: 3rd.

Wawro, K., E. Wilkiewicz-Wawro, I. Prusinowska, A. Koncicki and A. Krasnodebska-Depta, 2000. The selected blood indices of Muscovy and Pekin ducks and their crossbreds and evaluation of heterosis effect. Zesz. Nauk. PTZ 49: 177-190.

Yamamoto, Y. and B. Glick. 1982. A comparison of the immune response between two lines of chickens selected for differences in the weight of the bursa of Fabricius. Poult. Sci., 61: 2129-2132. 